\title{
ESTRUTURA ICTIOFAUNÍSTICA NA ZONA LITORÂNEA DE UM LAGO URBANO NA BACIA DO RIO IVAÍ
}

\author{
Fagner de Souza* \\ Edson Fontes de Oliveira** \\ João Paulo Alves Pagotto*** \\ Carlos Eduardo da Silva****
}

\begin{abstract}
RESUMO: O estudo teve como objetivo promover o levantamento da ictiofauna do lago Jaboti, situado na cidade de Apucarana, Paraná, Brasil. As coletas foram realizadas bimestralmente, entre abril de 2010 e março de 2011, em cinco pontos de amostragem. No total, foram capturados 22.489 indivíduos, distribuídos em cinco ordens, seis famílias e sete espécies. Poecilia reticulata foi a espécie mais representativa em termos de abundância. Esta espécie apresenta adaptações morfológicas e fisiológicas que conferem maior tolerância às alterações ambientais antrópicas. Deste modo, foi constatado que esta espécie pode ser considerada bioindicadora e que o lago Jaboti sofre uma avançada degradação ambiental ao longo de todo o seu perímetro.
\end{abstract}

PALAVRAS-CHAVE: Apucarana; Bacia do Alto Rio Paraná; Lago Artificial; Lago Jaboti; Poecilia reticulata.

\section{ICHTHYOFAUNA STRUCTURE ON THE LITTORAL ZONE OF AN URBAN LAKE IN THE RIVER IVAÍ BASIN}

ABSTRACT: A survey of the ichthyofauna of the lake Jaboti in the town of Apucarana PR Brazil is undertaken. Collections were done every two months, between April 2010 and March 2011, at five sampling sites. Further, 22,489 specimens, distributed into five orders, six families and seven species were harvested. Poecilia reticulata was the most abundant species, featuring morphological and physiological adaptations with more tolerance to anthropic environmental changes. The species may be considered

\footnotetext{
* Biólogo; Doutorando em Ciências Ambientais pelo Programa de Pós-graduação em Ecologia de Ambientes Aquáticos Continentais na Universidade Estadual de Maringá - UEM, Maringá (PR), Brasil; E-mail: gnaofagner@hotmail.com

** Doutor em Ecologia de Ambientes Aquáticos Continentais Universidade Estadual de Maringá - UEM, Maringá (PR), Brasil; Docente na Universidade Tecnológica Federal do Paraná, Campus Londrina, (PR), Brasil.

**** Doutor em Ecologia de Ambientes Aquáticos Continentais e Docente da Faculdade Integrado de Campo Mourão, (PR), Brasil.

${ }^{* * * * *}$ Mestre em Tecnologia em Alimentos e Docente da Faculdade de Apucarana - FAP, Apucarana, (PR), Brasil.
} 
a bio-indicator since lake Jaboti undergoes a progressive environmental degradation throughout its perimeter.

KEY WORDS: Apucarana; High River Paraná Basin; Artificial Lake; Lake Jaboti; Poecilia reticulata.

\section{INTRODUÇÃO}

O crescimento populacional tem causado efeitos danosos aos recursos hídricos, devido, especialmente, ao escoamento de resíduos agropecuários, industriais e domésticos sobre os ecossistemas aquáticos (CUNICO et al., 2012). Neste contexto, estudos que indiquem o estado de conservação das condições ambientais de corpos d'água continentais são fundamentais para qualquer estratégia de manejo e recuperação ambiental (WINEMILLER et al., 2008). Desse modo, o conhecimento acerca da composição de espécies de um determinado ecossistema aquático pode contribuir para indicar as condições ambientais e, por conseguinte, o estado de conservação do local (CASATTI et al., 2006).

O continente sul-americano possui uma ictiofauna altamente diversificada, com aproximadamente 60 famílias, centenas de gêneros e mais de 5.000 espécies, sendo Characiformes e Siluriformes os grupos dominantes (REIS et al., 2003). Na região sul do Brasil, este cenário se repete, porém, a interferência antrópica sobre os corpos d'água da região, especialmente aqueles inseridos em áreas urbanizadas, tem propiciado um aumento significativo na ocorrência de espécies exóticas sobre tais ecossistemas (CUNICO, 2010).

Nas grandes cidades, a preocupação com a qualidade da água e com a composição da biodiversidade tem aumentado significativamente (CUNICO et al., 2012). Por esta razão, inventários de espécies necessitam ser executados nos corpos d'água urbanos, sobretudo lagos e riachos, onde as marcantes alterações ambientais tendem a afetar adversamente a assembleia de peixes (SCHUELER; SIMPSON, 2001).

Portanto, este estudo teve como principal objetivo promover o levantamento das espécies de peixes na zona litorânea do lago Jaboti, no município de Apucarana, Paraná, Brasil, propiciando, assim, informações sobre a composição da ictiofauna local e comentários sobre impactos entre os pontos amostrados, fornecendo 
subsídios aos possíveis e desejáveis planos de manejo que possam ser desenvolvidos no futuro.

\section{MATERIAIS E MÉTODOS}

\section{1 ÁREA DE ESTUDO}

O lago Jaboti (23034'00"S/51028'26"W), originalmente criado com o intuito de proporcionar opções de lazer para a população da cidade de Apucarana, ocupa área de $140.000 \mathrm{~m}^{2}$, sendo $700 \mathrm{~m}$ de comprimento e $200 \mathrm{~m}$ de largura. Seus principais corpos d'água formadores são os córregos Jaboti, Água da Lagoa e Barra Nova, todos afluentes do rio Ivaí, bacia do alto rio Paraná (MANOSSO, 2005).

No total, cinco pontos de amostragem foram estabelecidos na zona litorânea do lago Jaboti, dos quais três são na desembocadura dos córregos tributários do lago e dois pontos próximos à barragem em margens opostas (Figura 1).

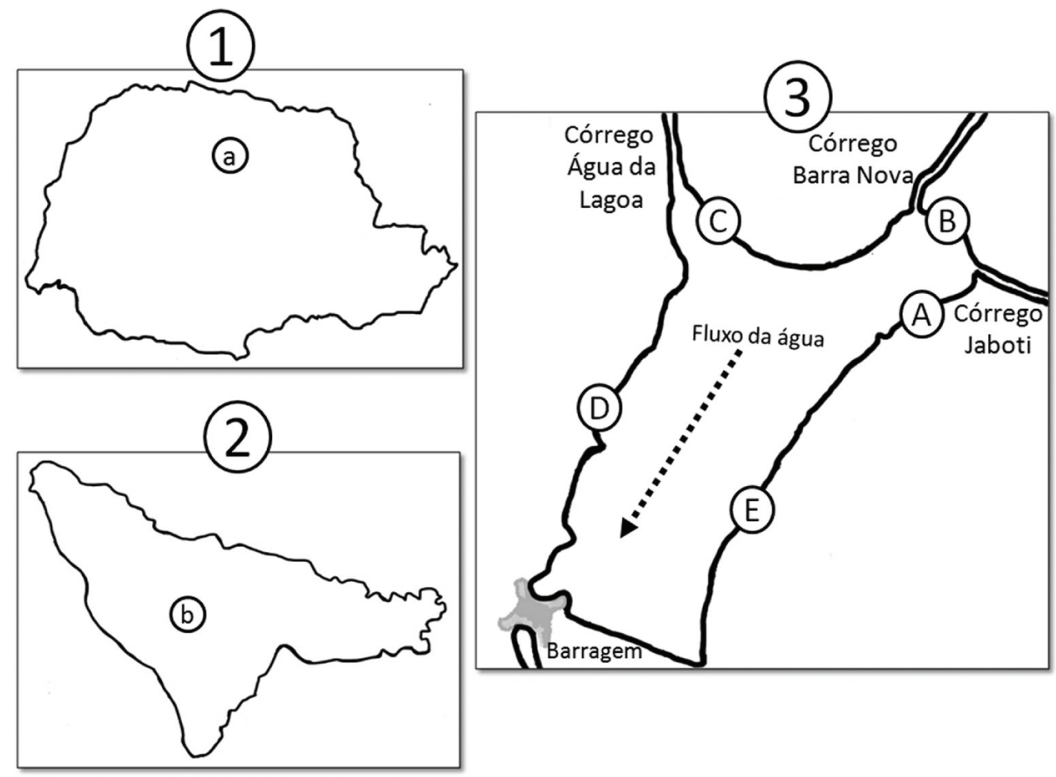

Figura 1. (1) Mapa do Estado do Paraná, com (a) localização geográfica do município de Apucarana dentro do Estado. (2) Mapa do Município de Apucarana, com (b) localização geográfica do Lago Jaboti dentro do Município. (3) Mapa esquemático do Lago Jaboti com localizações dos pontos de amostragem. (A) Ponto A, (B) Ponto B, (C) ponto C, (D) ponto D e (E) ponto $\mathrm{E}$. 
Ponto A: localizado na desembocadura do córrego Jaboti, possui margens tomadas por gramíneas e solo compactado pelo pisoteio de pessoas e capivaras. $\mathrm{O}$ leito é compactado e firme, porém com poucas rochas.

Ponto B: localizado na foz do córrego Barra Nova, possui margens tomadas por gramíneas e vegetação herbácea. O solo da margem encontra-se compactado devido à intensa visitação e no local há a presença de resíduos relacionados às atividades de lazer, como a pesca. O leito é arenoso e instável.

Ponto C: localizado na foz do córrego Água da Lagoa, onde a margem é ocupada por gramíneas, vegetação herbácea e arbórea. O leito é arenoso e instável, a presença de macrófitas aquáticas é registrada no local.

Ponto D: localizado na margem direita do lago, onde há bambuzais e uma forte dominância de gramíneas. O leito é tipicamente rochoso.

Ponto E: localizado próximo a uma área destinada às atividades de lazer com leito muito rochoso. Sua margem é ocupada, principalmente, por gramíneas, porém algumas árvores, tais como cerejeiras, ocorrem no local.

\subsection{VARIÁVEIS ABIÓTICAS}

Como variáveis abióticas foram coletados os seguintes parâmetros: potencial hidrogeniônico $(\mathrm{pH})$, concentração de oxigênio dissolvido (OD), concentração de fosfato $\left(\mathrm{PO}_{4}\right)$ e demanda química de oxigênio (DQO).

Para a obtenção do $\mathrm{pH}$ das amostras foi utilizado um eletrodo de vidro e o "pHmetro". Já para obtenção do oxigênio dissolvido das amostras coletadas foi utilizado um aparelho denominado oxímetro. Todos os valores foram utilizados com apenas uma casa decimal após a vírgula.

Para a obtenção da concentração de fosfato nas amostras foi realizado o método colorimétrico com auxílio do espectrofotômetro, usando como reagente o cloreto de estanho, com medidas espectrofotométricas com 690 nanômetros, a partir dos seguintes materiais: Indicador fenolftaleína $0,1 \%$; Solução ácido forte $\mathrm{H}_{2} \mathrm{SO}_{4}$. $\mathrm{HNO}_{3}$; Solução de molibdato de amônio; Solução de cloreto estanoso; Solução de hidróxido de sódio $1 \mathrm{~mol} \mathrm{~L}^{-1}$; Solução padrão de fosfato. $\mathrm{O}$ procedimento adotado seguiu as seguintes etapas: (a) transferida a água do lago através de filtro para o 
béquer; (b) adicionada uma gota de fenolftaleína; (c) acidificado com solução de ácido forte; (d) aquecido ao ponto de ebulição por 90 minutos; (e) completado o volume com água destilada; (f) após o resfriamento, adicionada solução de hidróxido de sódio até a coloração de rósea sob agitação; (g) adicionada solução de molibdato de amônio; (h) agitado bem e logo em sequência adicionar a solução de cloreto estanosso; (i) após 10 a 12 minutos efetuando a leitura no espectrofotômetro, usado para calibrar água destilada que passou pelo mesmo processo.

$\mathrm{Na}$ análise do DQO foram executados os seguintes procedimentos com auxílio do espectrofotômetro: em um tubo de ensaio foram adicionados $2 \mathrm{ml}$ de solução de DQO (K2Cr2O7) em cada tubo; Adição de 1,5 ml da amostra (água coletada nos pontos do lago) em cada tubo; Adição de 1,5 ml de água destilada em cada tudo; Adição de $3 \mathrm{ml}$ de H2SO4/Ag2SO4 em cada tubo.

Toda a amostra de água do lago utilizada nos dados abióticos foi diluída com 1,5 ml de água destilada; após a leitura no espectrofotômetro a 600 nanômetros, seus dados foram somados e tiradas médias; logo após esta média, multiplicadas por 2 (dois), para exibir o real resultado da amostra.

\subsection{AMOSTRAGEM DA ICTIOFAUNA}

As coletas foram realizadas sob autorização do Instituto Brasileiro do Meio Ambiente e dos Recursos Naturais Renováveis (IBAMA) (22442-1DIFAP/IBAMA, Processo IBAMA \# 02040.000093/06-45).

Os peixes foram coletados na zona litorânea do lago com redes de arrasto de três tipos de malhagens $(0,5 ; 2,3$ e 6,0 mm entre nós adjacentes), e em seguida anestesiados, mortos (com Cloridrato de Benzocaína dissolvido em água, 100 $\mathrm{mL} 15 \mathrm{~L}$ ), fixados em formol 10\% e conservados em álcool $70^{\circ} \mathrm{GL}$.

Exemplares testemunhos foram depositados na Coleção Ictiológica do Núcleo de Pesquisas em Limnologia, Ictiologia e Aquicultura (Nupélia) da Universidade Estadual de Maringá. Bryconamericus aff. iheringi NUP 10009 (5 ex. 32,90-58,66SL); Hoplias sp.3 NUP 10012 (2 ex. 90,57-111,50SL), NUP 10013 (1 ex. 132,70SL), NUP 11986 (1 ex. 28,93SL), NUP 12072 (3 ex. 23,56-46,37SL), NUP 12073 (1 ex. 48,71SL); Poecilia reticulata NUP 10010 (7 ex. 14,25-25,02SL); Gymnotus 
sylvius NUP 12330 (1 ex. 197,52TL); Geophagus brasiliensis NUP 10014 (11 ex. 20,84-65,47SL); Tilapia rendali NUP 10011 (5 ex. 23,31-26,10SL); Hypostomus cf. Ancistroides NUP 12336 (1 ex. 81,06SL) NUP 11983 (1 ex. 120SL).

\subsection{ANÁLISE DOS DADOS}

Em laboratório, os peixes foram identificados de acordo com Graça e Pavanelli (2007), e posteriormente analisados quanto ao número de indivíduos capturados, o número de indivíduos pertencentes a cada espécie, a contribuição percentual das espécies e o aporte percentual de cada ordem para a ictiofauna. As categorias taxonômicas superiores foram classificadas de acordo com Eschmeyer (2013), enquanto que as famílias e subfamílias são apresentadas de acordo com Reis et al. (2003).

Para verificar se os dados abióticos apresentaram diferenças significativas entre os pontos amostrados foi realizado o teste " $t$ " de Student. Para os dados bióticos de presença e ausência construiu-se uma matriz de similaridade de BrayCurtis, para verificar a similaridade de espécies entre os pontos amostrados. Também foi realizada uma análise de correlação entre os dados abióticos e a riqueza de cada ponto. Na análise de correlação os dados foram todos logaritmizados para retirar o efeito do tamanho das unidades. Os gráficos e dados estatísticos básicos foram todos realizados no programa Statistica versão 7.1 (STATSOFT, 2005).

A eficiência amostral foi testada através de uma curva de acumulação de espécies, com base nos valores de Mao Tau, gerados a partir de 100 aleatorizações. Tal procedimento foi realizado no programa Estimates versão 7.5.2 (COLWELL, 2005).

\section{RESULTADOS}

No total foram coletados 22.489 indivíduos, distribuídos em cinco ordens, seis famílias e sete espécies (Tabela 1). A maior ocorrência de indivíduos foi encontrada na ordem Cyprinodontiformes, 93,4\%; Perciformes, 5,3\%; e Characiformes, 1,4\% (Figura 2). 
Entre as espécies a maior abundância foi da espécie Poecilia reticulata Peters, 1859, 93,4\%; seguido por Geophagus brasiliensis (Quoy \& Gaimard, 1824), 5,3\%; e Tilapia rendalli (Boulenger, 1897), 1,4\% (Figura 3).

Tabela 1. Lista das espécies de peixes coletados na zona litorânea do lago Jaboti.

\begin{tabular}{|c|c|c|c|c|c|c|}
\hline Posição sistemática & A & B & $\mathrm{C}$ & D & $\mathbf{E}$ & Total \\
\hline \multicolumn{7}{|l|}{ Osteichthyes } \\
\hline \multicolumn{7}{|l|}{ Characiformes } \\
\hline \multicolumn{7}{|l|}{ Characidae } \\
\hline $\begin{array}{l}\text { Bryconamericus aff. iberingi } \\
\text { (Boulenger, 1887) }\end{array}$ & 132 & 12 & 35 & 20 & 102 & 301 \\
\hline \multicolumn{7}{|l|}{ Erythrinidae } \\
\hline Hoplias sp.3 & - & 05 & - & - & - & 05 \\
\hline \multicolumn{7}{|l|}{ Siluriformes } \\
\hline \multicolumn{7}{|l|}{ Loricariidae } \\
\hline $\begin{array}{l}\text { Hypostomus cf. ancistroides } \\
\text { (Ihering, 1911) }\end{array}$ & 01 & - & - & 01 & - & 02 \\
\hline \multicolumn{7}{|l|}{ Gymnotiformes } \\
\hline \multicolumn{7}{|l|}{ Gymnotidae } \\
\hline $\begin{array}{l}\quad \text { Gymnotus sylvius } \\
\text { Albert \& Fernandes-Matioli, } 1999\end{array}$ & 01 & - & - & - & - & 01 \\
\hline \multicolumn{7}{|l|}{ Cyprinodontiformes } \\
\hline \multicolumn{7}{|l|}{ Poeciliidae } \\
\hline Poecilia reticulata Peters, 1859 & 1.648 & 3.871 & 9.755 & 1.658 & 4.065 & 20.997 \\
\hline \multicolumn{7}{|l|}{ Perciformes } \\
\hline \multicolumn{7}{|l|}{ Cichlidae } \\
\hline $\begin{array}{l}\text { Geophagus brasiliensis } \\
\text { (Quoy \& Gaimard, 1824) }\end{array}$ & 96 & 281 & 98 & 75 & 85 & 635 \\
\hline Tilapia rendalli (Boulenger, 1897) & 185 & 32 & 70 & 58 & 203 & 548 \\
\hline Total & 2.063 & 4.201 & 9.958 & 1.812 & 4.455 & 22.489 \\
\hline
\end{tabular}




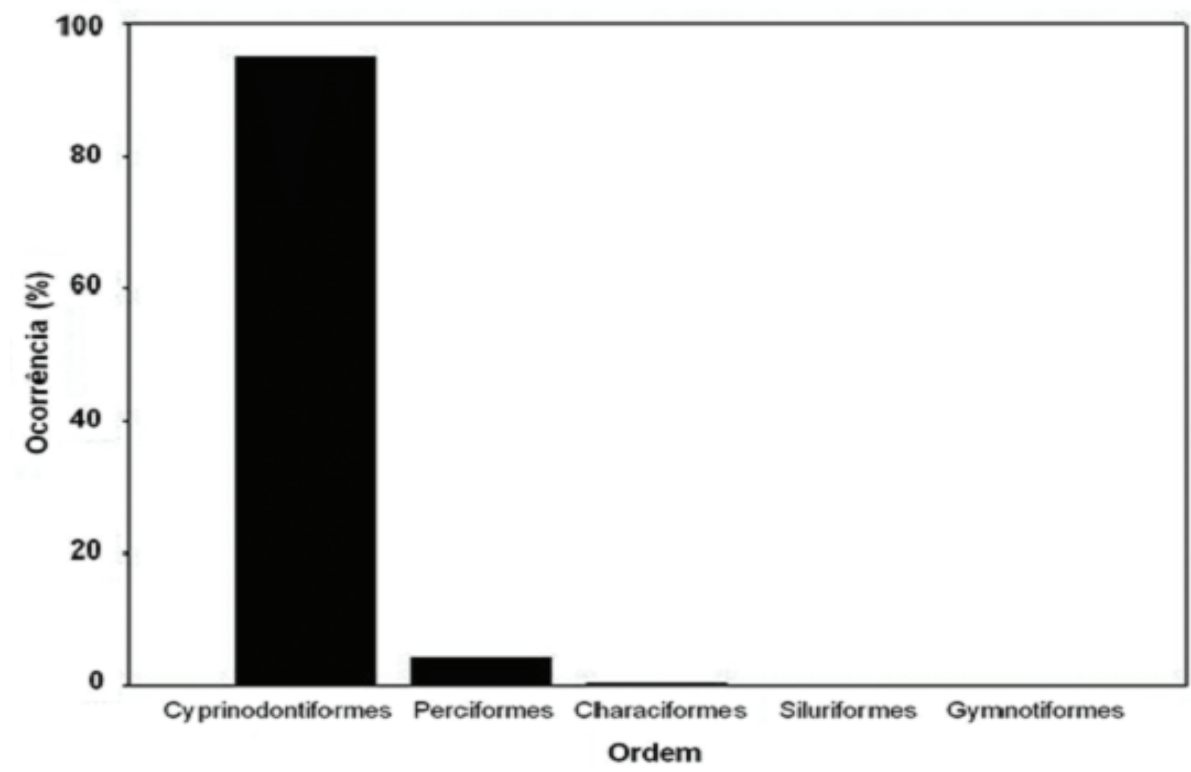

Figura 2. Relação da ocorrência de espécies por ordens

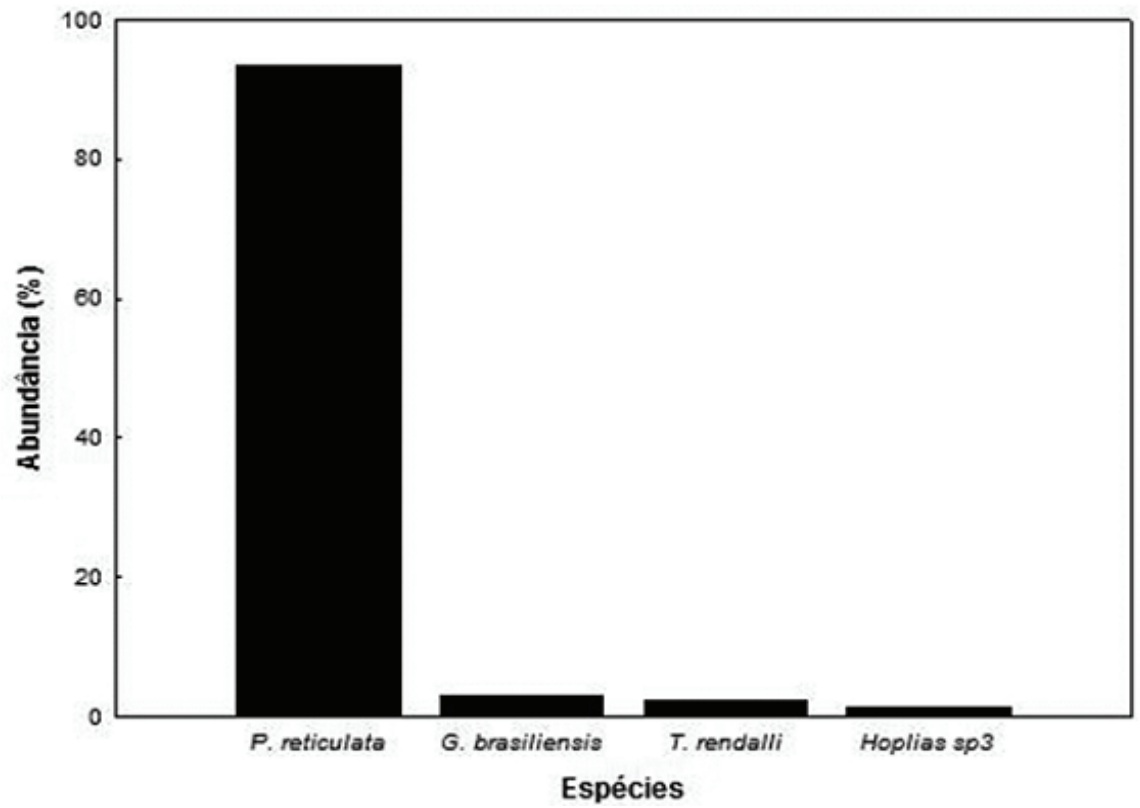

Figura 3. Distribuição da abundância das principais espécies coletadas no lago Jaboti. 
$\mathrm{Na}$ similaridade de espécies, o ponto $\mathrm{A}$ apresentou forte semelhança ao ponto E, da mesma forma foi para os pontos $\mathrm{C}$ e E. Contudo, o ponto B foi a assembleia mais diferente de todos os outros, apresentando uma grande distância em relação aos outros pontos (Figura 4). Na curva de acumulação de espécies, o lago Jaboti apresentou uma forte inclinação mostrando que está muito distante de atingir uma assíntota (Figura 5).

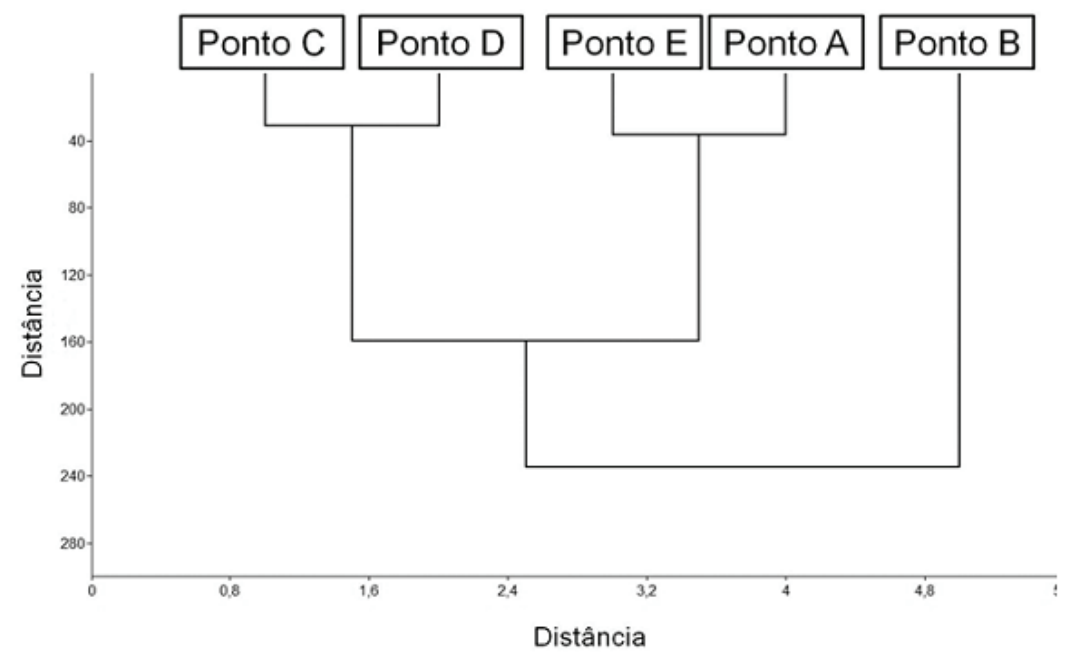

Figura 4. Similaridade de Bray-curtis de espécies entre os pontos amostrados no lago Jaboti.

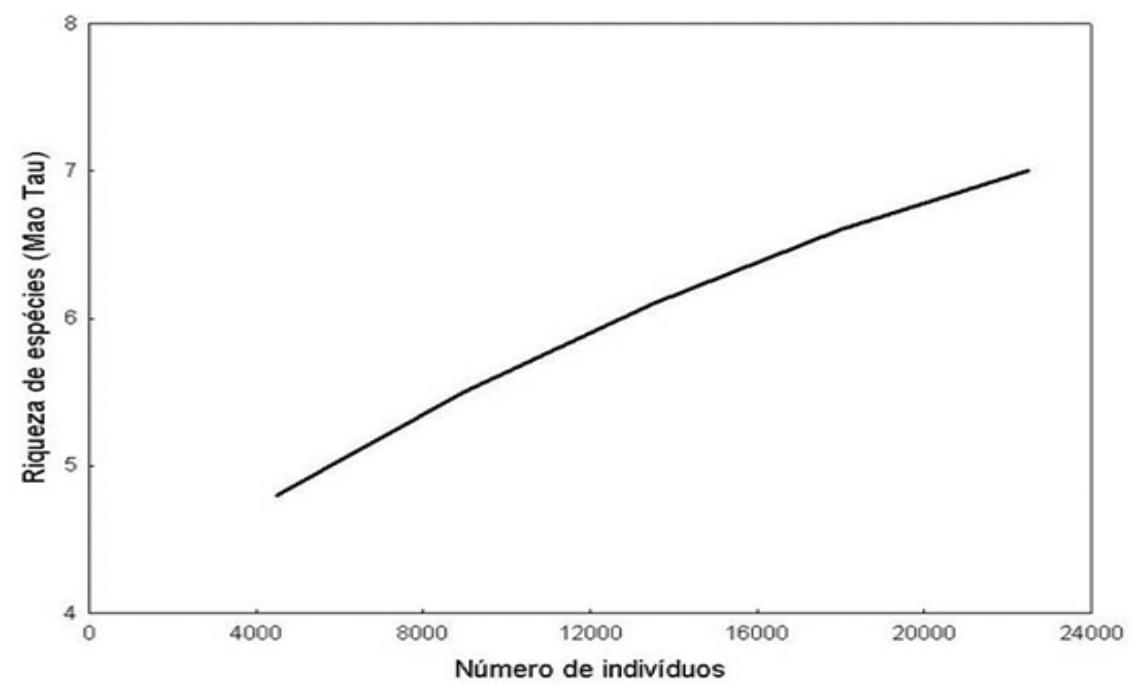

Figura 5. Curva de acumulação de espécies do Lago Jaboti. 
Tabela 2. Valores médios das variáveis abióticas e seus respectivos desvios padrões estimadas no Lago Jaboti.

\begin{tabular}{llllll}
\hline Variáveis & Ponto A & Ponto B & Ponto C & Ponto D & Ponto E \\
\hline$* \mathrm{PH}$ & $7,30 \pm 0,21$ & $6,43 \pm 0,38$ & $6,92 \pm 0,32$ & $7,30 \pm 0,20$ & $7,21 \pm 0,56$ \\
$* \mathrm{O}_{2}(\mathrm{mg} / \mathrm{L})$ & $5,98 \pm 2,56$ & $5,42 \pm 1,99$ & $3,94 \pm 2,86$ & $5,73 \pm 1,87$ & $5,64 \pm 1,99$ \\
$* \mathrm{DQO}(\mathrm{mg} / \mathrm{L})$ & $73,45 \pm 96,50$ & $85,60 \pm 79,94$ & $182,32 \pm 148,97$ & $61,47 \pm 31,48$ & $71,89 \pm 79,54$ \\
${ }^{*} \mathrm{PO}_{4}(\mathrm{mg} / \mathrm{L})$ & $0,12 \pm 0,10$ & $0,08 \pm 0,10$ & $0,16 \pm 0,14$ & $0,36 \pm 0,37$ & $0,40 \pm 0,46$ \\
\hline
\end{tabular}

*significativo $(\mathrm{p}<0,05)$.

Nos dados abióticos foram encontradas diferenças significativas entre todos os pontos amostrados (Tabela 2). Os valores mais altos para o potencial hidrogeniônico $(\mathrm{pH})(\mathrm{p}=0,000002)$ foram encontrados nos pontos A e D $(7,30 \mathrm{em}$ ambos), e para o oxigênio dissolvido (OD) $(\mathrm{p}=0,0001)$ foi o ponto A $(5,98 \mathrm{mg} / \mathrm{L})$. Já os valores mais baixos neste mesmo parâmetro foram encontrados no ponto $\mathrm{C}$, respectivamente 6,92 (pH) e 3,94 (OD). Neste mesmo ponto foram encontrados os valores mais altos de demanda química de oxigênio $(\mathrm{p}=0,013), 182,32 \mathrm{ml} / \mathrm{L}$, e os menores valores no ponto $\mathrm{D}, 61,47 \mathrm{ml} / \mathrm{L}$. Já para os valores de concentração de fosfato $(\mathrm{p}=0,026)$, o ponto $\mathrm{D}$ foi o que apresentou maiores valores neste parâmetro, $0,40 \mathrm{mg} / \mathrm{L}$, e menores valores foram para o ponto $\mathrm{B}, 0,08 \mathrm{ml} / \mathrm{L}$.

Estes dados, quando relacionados à estrutura da assembleia, apresentaram uma pequena correlação positiva entre a riqueza e os dados abióticos (Figura 6), porém esta correlação não foi significativa (Tabela 3). 


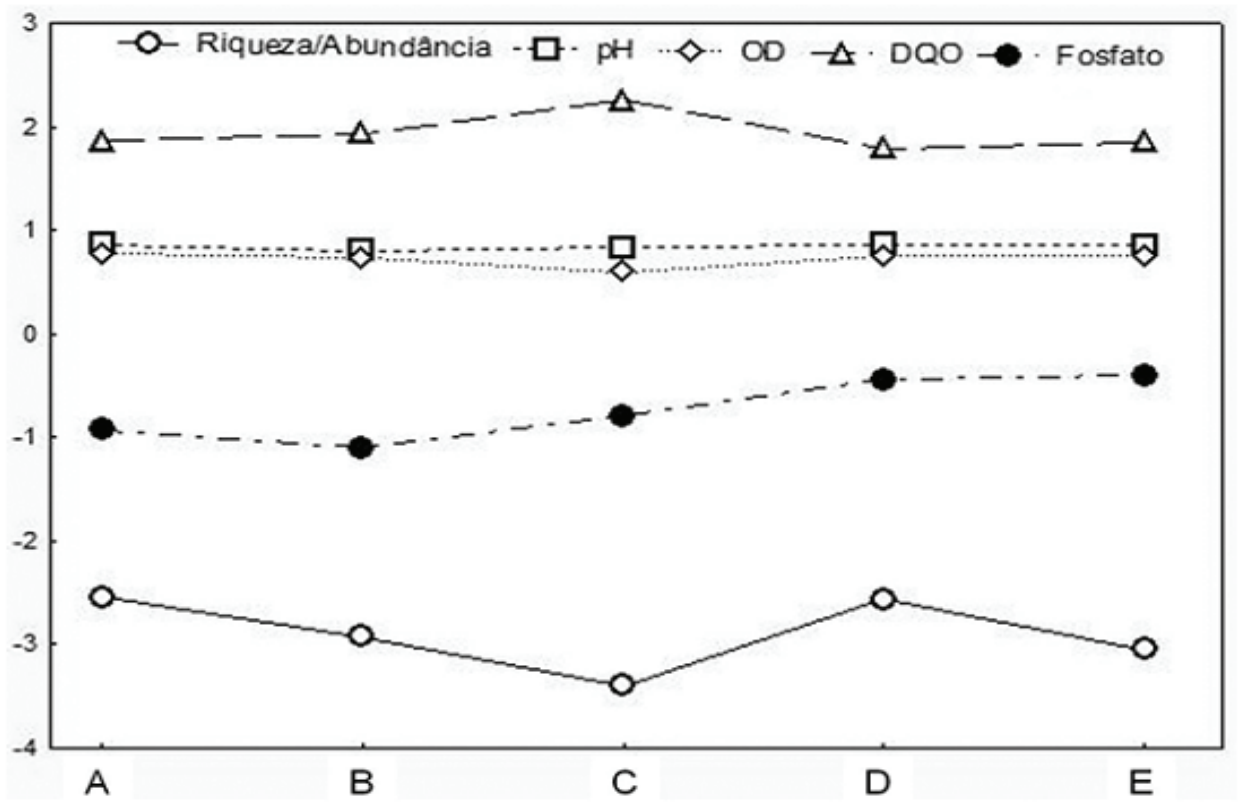

Figura 6. Correlação de Pearson-r entre a riqueza de espécies e os dados abióticos amostrado no lago Jaboti. Potencial hidrogeniônico $(\mathrm{pH})$, concentração de oxigênio dissolvido $\left(\mathrm{O}_{2}\right)$, demanda química de oxigênio (DQO) e concentração de fosfato $\left(\mathrm{PO}_{4}\right)$.

Tabela 3. Correlação de Pearson-r entre a riqueza de espécies e os dados abióticos amostrado no lago Jaboti. Potencial hidrogeniônico $(\mathrm{pH})$, concentração de oxigênio dissolvido $\left(\mathrm{O}_{2}\right)$, demanda química de oxigênio (DQO) e concentração de fosfato $\left(\mathrm{PO}_{4}\right)$.

\begin{tabular}{lcc}
\hline Correlação de Pearson & Valor do $\mathbf{r}$ & Valor do $\mathbf{p}$ \\
\hline Riqueza $\times$ pH & 0,1213 & 0,8459 \\
Riqueza $\times$ OD & 0,6352 & 0,2495 \\
Riqueza x DQO & $-0,5166$ & 0,3728 \\
${\text { Riqueza } \times \mathbf{P O}_{4}}$ & $-0,4519$ & 0,4449 \\
\hline
\end{tabular}

\section{DISCUSSÃO}

Diferentemente da tendência apresentada por outros corpos d'água da bacia hidrográfica do alto rio Paraná que, de modo geral, possuem a maioria 
de seus indivíduos pertencentes à Characiformes e Siluriformes (LANGEANI et al., 2007), a zona litorânea do lago Jaboti apresentou uma ampla dominância de Cyprinodontiformes (Figura 2).

Essa tendência foi determinada pela maior abundância de Poecilia reticulata sobre as demais espécies (Figura 3). Resultados semelhantes foram registrados por outros autores em estudos sobre a ictiofauna de corpos d'água urbanos da bacia do alto rio Paraná (OLIVEIRA; BENNEMANN, 2005; CUNICO et al., 2006; 2009; PAGOTTO et al., 2012; SOUZA et al., 2013).

Assim como registrado por CUNICO et al. (2009), as modificações ambientais extremas sobre os corpos d'água urbanizados tendem a possibilitar uma maior susceptibilidade destes ecossistemas à invasão de espécies não nativas e altamente tolerantes à degradação ambiental. Fato este também observado em nossos dados, nos quais os ambientes com os dados abióticos mais alterados apresentaram esta mesma característica.

No presente estudo, a somatória da abundância de $P$. reticulata e Tilapia rendali, oriundas, respectivamente, da Venezuela e do continente africano (GRAÇA; PAVANELLI, 2007), totalizaram mais de 95\% dos indivíduos capturados. Neste caso, a ocorrência de T. rendali no lago Jaboti, assim como para outros corpos d'água da bacia do alto rio Paraná, talvez possa estar relacionada ao escape de alguns indivíduos de tanques de piscicultura localizados ao longo da referida bacia (LANGEANI et al., 2007). Todavia, não se pode descartar a possibilidade de soltura de espécimes para fins de entretenimento, uma vez que o lago é frequentemente utilizado pela população local para atividades de lazer, como a pesca (observação pessoal).

Por outro lado, a elevada abundância de $P$. reticulata se deve à sua notável tolerância às modificações ambientais antrópicas, marcantes ao longo das margens e da zona litorânea do lago Jaboti, como pisoteio por animais, ausência de vegetação arbórea, presença de resíduos sólidos, assoreamento, poluição orgânica e eutrofização. A presença desta espécie se mostra muito interessante, pois esta possui adaptações morfológicas e fisiológicas que lhe permitem obter oxigênio dissolvido diretamente das camadas superficiais da coluna d'água (BOOCK; MACHADO NETO, 2005). Por esse motivo esta espécie é considerada como bioindicadora de corpos d'água degradados (CROUX et al., 2002; SOUZA; TOZZO, 2013).

Embora, no presente estudo, tenha sido coletado um número expressivo 
de indivíduos, o mesmo ainda necessita de um esforço maior de captura, como indicado pela curva de acumulação de espécies (Figura 4). A não ocorrência de uma assíntota nesta análise indica que novas espécies tendem a ser encontradas. Mesmo se considerando a zona litorânea uma das regiões com maior diversidade de espécies em ambientes lacustres (ESTEVES, 1998; OLIVEIRA et al., 2001), neste caso, a expansão das amostragens para áreas ainda não exploradas do lago, como as regiões de meio, ou então, a realização de estudos contínuos ao longo dos anos, poderiam fornecer resultados mais completos e precisos acerca da composição da ictiofauna.

\section{CONSIDERAÇÕES FINAIS}

Notadamente a intensa dominância da espécie $P$. reticulata, tolerante às alterações ambientais antrópicas, pode-se considerá-la como bioindicadora da degradação ambiental recorrente ao longo de todo o perímetro do lago. Este fato sugere que medidas de restauração da qualidade da água dos córregos formadores do lago, bem como ações de reestruturação da vegetação marginal e programas de educação ambiental, devem estar presentes em qualquer plano de manejo que possa ser desenvolvido para recuperação ambiental da área.

\section{AGRADECIMENTOS}

À Dra. Carla Simone Pavanelli (Universidade Estadual de Maringá) e Ms. Rafaela Priscila Ota, pelo auxílio na identificação dos peixes. Ao Instituto Brasileiro do Meio Ambiente e dos Recursos Naturais Renováveis (IBAMA) e à Secretaria do Meio Ambiente e Turismo de Apucarana (SEMATUR), especialmente ao secretário João Batista Beltrame, pela permissão das coletas. À Dra. Evanilde Benedito e ao Dr. Claudio H. Zawadzki (ambos da Universidade Estadual de Maringá) pelo empréstimo dos equipamentos de pesca. À Faculdade de Apucarana (FAP) e ao PEA/Nupélia/ UEM, pelo apoio logístico. J. P. A. Pagotto e F. Souza agradecem à Coordenação de 
Aperfeiçoamento de Pessoal de Nível Superior (CAPES/Ministério da Educação) pelo financiamento.

\section{REFERÊNCIAS}

BOOCK, M. V.; MACHADO NETO, J. G. Estudo sobre toxicidade aguda de oxicloreto de cobre para o peixe Poecilia reticulata. Boletim do Instituto de Pesca, São Paulo, v. 33, p. 29-35, 2005.

CASATTI, L.; LANGEANI, F.; SILVA, A. M.; CASTRO, R. M. C. Stream fish, water and habitat quality in a pasture dominated basin, Southeastern Brazil. Brazilian Journal of Biology, v. 66, n. 2b, p. 681-696, 2006.

COLWELL, R. K. EstimateS: Statistical estimation of species richness and shared species from samples. Version 7.5.2. 2005. Disponível em: < http://viceroy.eeb. uconn.edu/EstimateSPages/EstimateSRegistration.htm > Acesso em: set. 2011.

CROUX, M. J. P.; LOTESTE, A.; CAMPANA, M. Toxidad Aguda del piretroide cipermetrina em Poecilia reticulata y Cynesterodon decemmaculatus (Pisces, Poeciliidae); Revista FABICIB, v. 6, p. 69-74, 2002.

CUNICO, A. M.; AGOSTINHO, A. A.; LATINI, J. D. Influência da urbanização sobre as assembléias de peixes em três córregos de Maringá, Paraná. Revista Brasileira de Zoologia, v. 23, n. 4, p. 1101-1110, 2006.

CUNICO, A. M.; GRAÇA, W. J.; AGOSTINHO, A. A.; DOMINGUES, W. M.; LATINI, J. D. Fish, Maringá Urban Streams, Pirapó River drainage, Upper Paraná River Basin, Paraná State, Brazil. Check List, v. 5, n. 2, p. 273-280, 2009.

CUNICO, A. M. Efeitos da urbanização sobre a estrutura das assembléias de peixes em córregos do município de Maringá, Paraná, Brasil. 2010. 73 f. Tese (Doutorado em Ecologia) - Universidade Estadual de Maringá. Departamento de Ciências Biológicas, Maringá. 2010. 
CUNICO, A. M.; FERREIRA E. A.; AGOSTINHO, A. A.; BEAUMORD, A. C.; FERNANDES, $R$. The effects of local and regional environmental factors on the structure of fish assemblages in the Pirapó Basin, Southern Brazil. Landscape and Urban Planning, v. 105, n. 3, p. 336-344, 2012.

ESCHMEYER, W. N. (ed). GENERA, SPECIES, REFERENCES. Disponível em: $<$ http://research.calacademy.org/research/ichthyology/catalog/fishcatmain.asp > . Acesso em: 19 set. 2013.

ESTEVES, F. de A. Fundamentos de limnologia; $2^{\mathrm{a}}$ edição. Rio de Janeiro: Editora Interciência LTDA, 1998. 790p.

GRAÇA, W. J.; PAVANELLI, C. S. Peixes da planície de inundação do alto rio Paraná e áreas adjacentes. Maringá: EDUEM, 2007. 241p.

LANGEANI, F.; CASTRO, R. M. C.; OYAKAWA, O. T.; SHIBATTA, O. A.; PAVANELLI, C. S.; CASATTI, L. Diversidade da ictiofauna do Alto Rio Paraná: composição atual e perspectivas futuras. Biota Neotropica, v. 7, n. 3, p. 1-17, 2007.

MANOSSO, F. C. Estudo da paisagem no município de Apucarana-Pr: Relação entre a estrutura geoecológica e a organização do espaço. 2005. 117f. Dissertação (Mestrado em Geografia) - Universidade Estadual de Maringá. Departamento de Geografia, Maringá. 2005.

OLIVEIRA, E. F.; LUIZ, E. A.; AGOSTINHO, A. A.; BENEDITO-CECILIO, E. Fish assemblages in littoral areas of the upper Paraná river floodplain, Brazil. Acta Scientiarum, v. 3, n. 2, p. 369-376, 2001.

OLIVEIRA, D. C.; BENNEMANN, S. T. Ictiofauna, recursos alimentares e relações com as interferências antrópicas em um riacho urbano no sul do Brasil. Biota Neotropica, v. 5, n. 1, p. 95-107, 2005.

PAGOTTO, J. P.; VERÍSSIMO, S.; GOULART, E.; MISE, F. T. Fishes (Osteichthyes: Actinopterygii) from the Pirapó river drainage, upper Paraná River basin, Paraná state, Brazil. Check List, v. 8, n. 3, p. 463-468, 2012. 
REIS, R. E.; KULLANDER, S. O.; FERRARIS Jr., C. J. Check list of the freshwater fishes of South and Central America. Porto Alegre: EDIPUCRS, 2003. 742p.

SCHUELER, T.; SIMPSON, J. Why urban lakes are different. Urban Lake Management, v. 3, n. 4, p. 747-750, 2001.

SOUZA, F.; ABREU, J. A. S.; SILVA, C. E.; GOUVEIA, A. A. Relação entre parâmetros ecológicos e qualidade ambiental em três córregos na bacia do alto rio Paraná. Biotemas, v. 26, n. 4, p. 101-110, 2013.

SOUZA, F.; TOZZO, R. A. Poecilia reticulata Peters 1859 (Cyprinodontiformes, Poeciliidae) como possível bioindicador de ambientes degradados. Revista Meio Ambiente e Sustentabilidade. v. 3, n. 2, p. 163-175, 2013.

STATSOFT. Statistica (data analysis software system). Version 7.1. 2005.

WINEMILLER, K. O.; AGOSTINHO, A. A.; CARAMASCHI, E. P. Fish ecology in tropical streams. In: DUDGEON, D. (Ed.). Tropical Stream Ecology. San Diego: Elsevier/ Academic Press, 2008. p. 107-146.

Recebido em: 26 de março de 2014 Acesso em: 07 de julbo de 2014 